九州大学学術情報リポジトリ

Kyushu University Institutional Repository

\title{
Effect of Respiration on Bioelectric Potential on the Surface of Tomato Eruit Harvested
}

Uchino, Toshitaka

Nakaji, Ke i

Laboratory of Agricultural Ecology, Division of Agricultural Ecology, Department of Plant Resources, Faculty of Agriculture, Kyushu University

Yasunaga, Eriko

Biotron institute, Kyushu University

Nakao, Kenzo

Nippon Flour Mills Co., Ltd.

他

https://doi.org/10.5109/4637

出版情報：九州大学大学院農学研究院紀要. 50 (1)，pp. 201-212，2005-02-01. Faculty of Agriculture, Kyushu University

バージョン :

権利関係 : 


\title{
Effect of Respiration on Bioelectric Potential on the Surface of Tomato Fruit Harvested
}

\author{
Toshitaka UCHINO*, Kei NAKAJI', Daisuke NEI ${ }^{2}$, \\ Eriko YASUNAGA ${ }^{3}$ and Kenzo NAKAO ${ }^{4}$
}

\begin{abstract}
Laboratory of Postharvest Science, Division of Bioproduction System Science, Department of Bioproduction Environmental Sciences, Faculty of Agriculture, Kyushu University, Fukuoka, 812-8581, Japan

(Received November 5, 2004 and accepted November 11, 2004)
\end{abstract}

\begin{abstract}
The bioelectric potentials on the surface (surface potential) of harvested tomato fruits were determined under various conditions. The effects of temperature and respiration rate on the surface potential were also investigated. The surface potential of the fruit slightly and irregularly changed with elapsed time at a constant temperature, however drastically changed with temperature rise except for under anoxia. In addition, the pattern of surface potential at the early stage of climacteric at a constant temperature was similar to that changing with temperature rise. Therefore, it appears that the change in surface potential with temperature depends not on passive diffusion potential but on respiration-dependent electrogenic potential.
\end{abstract}

\section{INTRODUCTION}

Many studies on the application of bioelectric potential to obtain the information from higher plants have been carried out. In these research the monitoring of bioelectric potential in a plant under various environmental conditions (Uchida et al., 1990; Intabon et al., 1996) and the observation of electrical signaling by the plant as a response to artificial stimulus (Miwa et al., 1992; Fromm and Bauer, 1994; Fromm et al., 1995; Fromm and Fei, 1998) were performed using a preharvest plant in a field. The bioelectric reactions of the growing plant have gradually become clear, so that it has been applied to determine the inorganic nutritional condition of tomato (Nakabayashi and Matsumoto, 1999; Nakabayashi et al., 2000). However, there has been a little work done to determine the bioelectric potential during maturation, ripening and storage of harvested crops such as fruits and vegetables (Kano and Yamaguchi, 1996). Morimoto et al. (1997) suggested that flexible control of the storage environment is effective in improving the quality of fruits. As the bioelectric potential has physiological information of the clops, it is possible to apply the potential as an index of quality of harvested fresh fruits and vegetables. If the potential is used as a signal for the control of storage environment, then the more

\footnotetext{
1 Laboratory of Agricultural Ecology, Division of Agricultural Ecology, Department of Plant Resources, Faculty of Agriculture, Kyushu University

2 Laboratory of Postharvest Science, Division of Bioproduction System Science, Department of Bioproduction Environmental Sciences, Graduate School of Bioresource and Bioenvironmental Sciences, Kyushu University

3 Biotron institute, Kyushu University

4 Nippon Flour Mills Co., Ltd.

* Corresponding author (E-mail: toshiu@bpes.kyushu-u.ac.jp)
} 
effective storage of fresh produce will be realized. The purpose of the present work is to obtain basic data of the bioelectric potential on the surface (surface potential) of tomato fruit and to investigate the relationship with its respiratory metabolism.

\section{MATERIALS AND METHODS}

\section{Plant materials}

Tomato fruits (Lycopersicon esculentum Mill) were obtained from a local farm or purchased from a supermarket in Fukuoka city, Japan. Samples were transported to the laboratory and held in a refrigerator until these attained to the experimental temperature.

\section{Experimental apparatus}

An experimental apparatus used for measuring the surface potential is shown in Fig. 1. An intact tomato fruit was set in a desiccator which was usually opened except for a case when gas concentration in it was measured. To determine the accurate surface potential, an input circuit was made on a substrate using operational amplifiers with a very high electric resistance of $10^{12} \Omega$ (Analog Devices Co., AD548). The input circuit had a reference point of the potential and 6 measuring channels as shown in Fig. 2. Capacitors were added for stabilizing the circuit and rheostat of $100 \mathrm{k} \Omega$ for adjusting offset voltage of each operational amplifier. The electrodes generally used for the electrocardiogram (Intabon et al., 1996) were attached to the surface of tomato fruit with

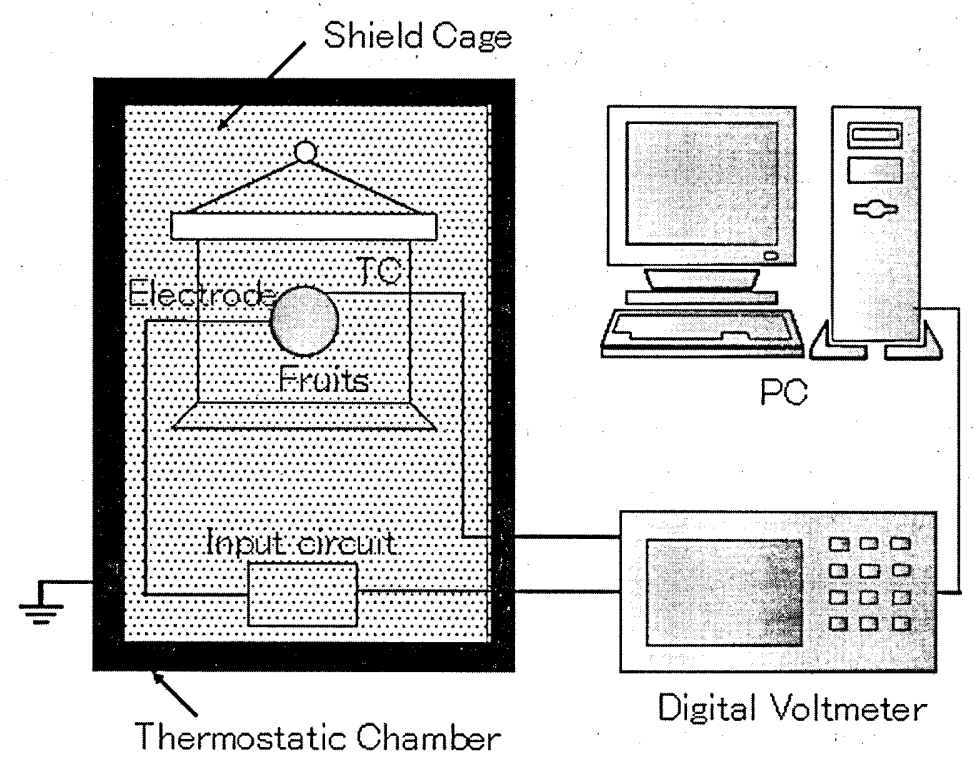

Fig. 1. Schematic diagram of experimental apparatus for measuring surface potential. TC: Thermocouple; PC: Personal computer; OP-Amp: Operational Amplifier. 


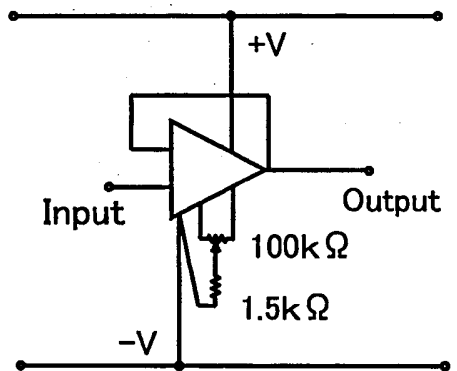

Details of Op-amplifier with offset adjuster

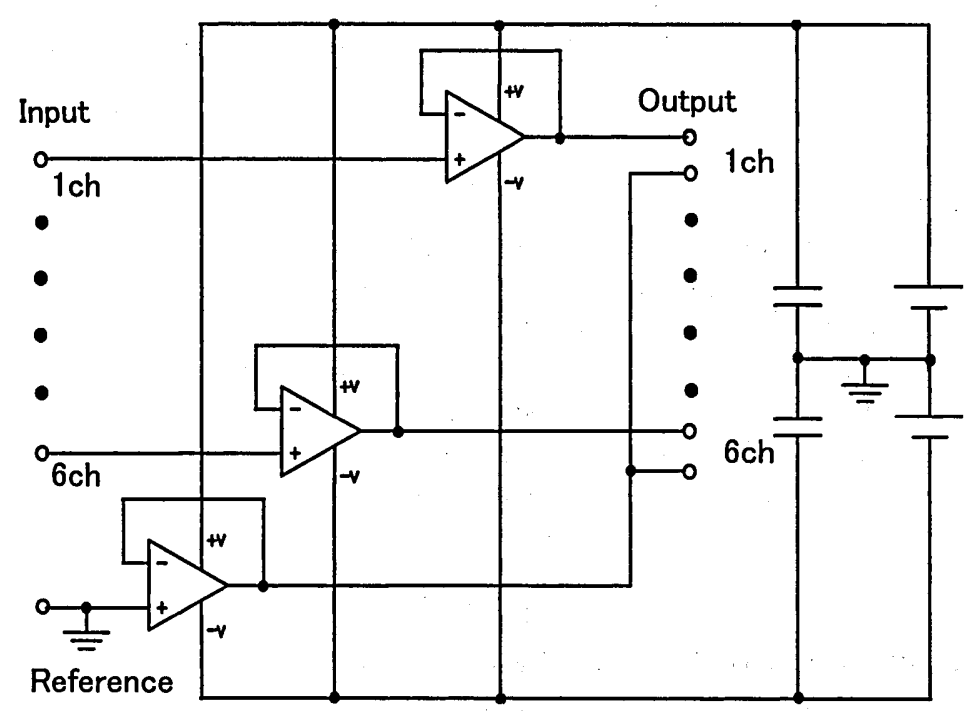

Fig. 2. Input circuit diagram.

conductive gel and connected to the terminals of reference and measuring channels of the input circuit. The electrodes were on the equator of tomato fruits at equal interval. A potential difference between the measuring and reference electrodes considering as the surface potential was measured by digital voltmeter and recorded in PC in 5 min interval. A tomato attached to electrodes in the desiccator and the input circuit were placed in an electric shielding cage made of aluminum angle bar and stainless-steel screen, and these were put in a programmable thermostatic chamber for controlling temperature (Fig. 1).

The linearity of output voltage of the circuit was tested by applying a voltage of 0 to $300 \mathrm{mV}$ to input terminal and the stability against temperature of the circuit was evaluated at a temperature changing periodically from 15 to $25^{\circ} \mathrm{C}$ every $24 \mathrm{~h}$ for $7 \mathrm{~d}$ in the thermostatic chamber. 
To separately evaluate each effect of temperature and respiration on the surface potential, four kinds of experiment which differed in temperature, ambient gas composition and respiratory condition were carried out (Table 1). Temperature in the desiccator was constant at $13{ }^{\circ} \mathrm{C}$ in experiment $\mathrm{l}$ and changed from 12.5 to $22.5^{\circ} \mathrm{C}$ in experiment 2. Tomato fruits were placed under anoxia in experiment 3, i.e. air in the desiccator replaced by over $99 \%$ nitrogen, and a respiratory climacteric rise of tomato fruits occurred in experiment 4.

Table 1. Experimental conditions.

\begin{tabular}{|c|c|c|c|}
\hline Experiment & Temperature $\left({ }^{\circ} \mathrm{C}\right)$ & Atmosphere & Respiration \\
\hline 1 & 13 (const.) & air & aerobic \\
\hline 2 & 12.5 to 22.5 & air & aerobic \\
\hline 3 & 14 to 23 & over $99 \% \mathrm{~N}_{2}$ & anaerobic \\
\hline 4 & 24.5 or 18 (const.) & air & $\begin{array}{l}\text { climacteric } \\
\text { (aerobic) }\end{array}$ \\
\hline
\end{tabular}

\section{Respiration rate}

In order to measure a respiration rate of tomato fruits, the desiccator was sealed with lid for $1 \mathrm{~h}$. A $1.0 \mathrm{ml}$ of gas sample was withdrawn by a gas-tight syringe from the head space of desiccator and injected into gas chromatograph equipped with thermal conductivity detector (GL Sciences GC-390, Tokyo Japan). Helium was used for carrier gas and the flow rate was $30 \mathrm{ml} \cdot \mathrm{min}^{-1}$. The injector and column temperatures were 80 and $50^{\circ} \mathrm{C}$, respectively. The respiration rate was calculated from the difference in the concentration of carbon dioxide gas between before and after sealing the desiccator.

\section{RESULTS}

\section{Results of input circuit test and preliminary test}

The linearity and stability of output voltage of the input circuit was tested. When 0 to $300 \mathrm{mV}$ of voltage was applied to the input circuit, the output voltages of 6 channels were same with the input voltage, moreover the linearity was very high as shown in Fig. 3. When $61 \mathrm{mV}$ of voltage was applied to the circuit at an ambient temperature changing from 15 to $25^{\circ} \mathrm{C}$ every $24 \mathrm{~h}$ for $7 \mathrm{~d}$, the variation of output voltage was only from 0.3 to $0.5 \mathrm{mV}$ (Fig. 4). During this 7 days test, the variation of output voltage depended on time course was little. From the results, the circuit had a significant stability to the temperature change and time course. The variation in output voltage of the input circuit caused by elapsed time and temperature change was neglected in present research since it was too small in comparison with surface potential of the produces.

Time course of surface potential of tomato fruit is shown in Fig. 5. Six measuring electrodes were attached to different positions on the tomato equator and connected to the input circuit. The surface potentials fluctuated with time. The potential in each channel was not same but similarly behaved in general. The relative position of measuring electrode to referring electrode did not affect the potential, namely the potential 


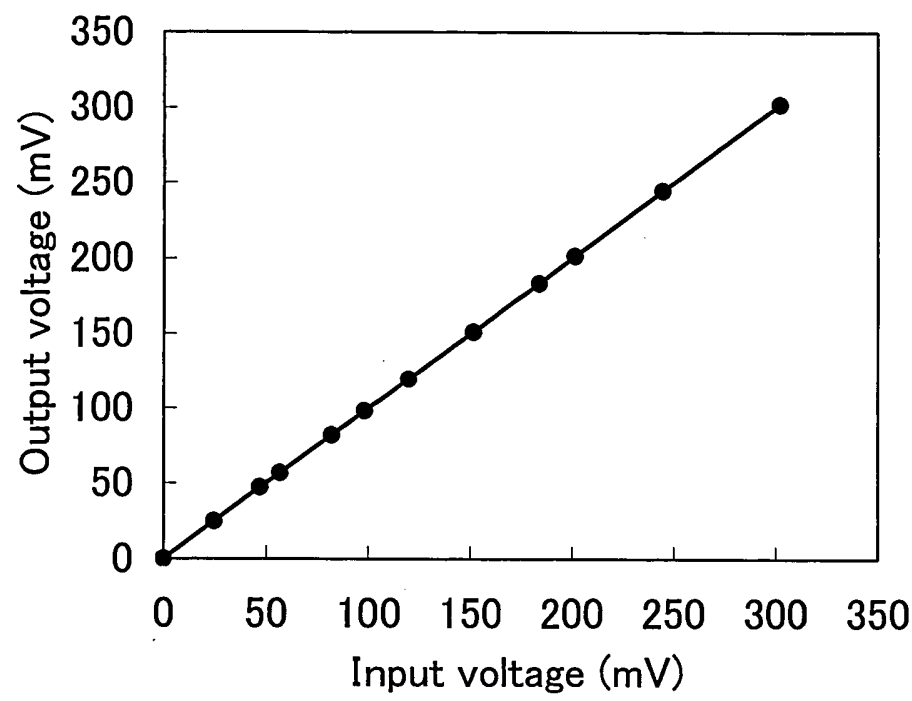

Fig. 3. Input-output characteristics of operational amplifier.

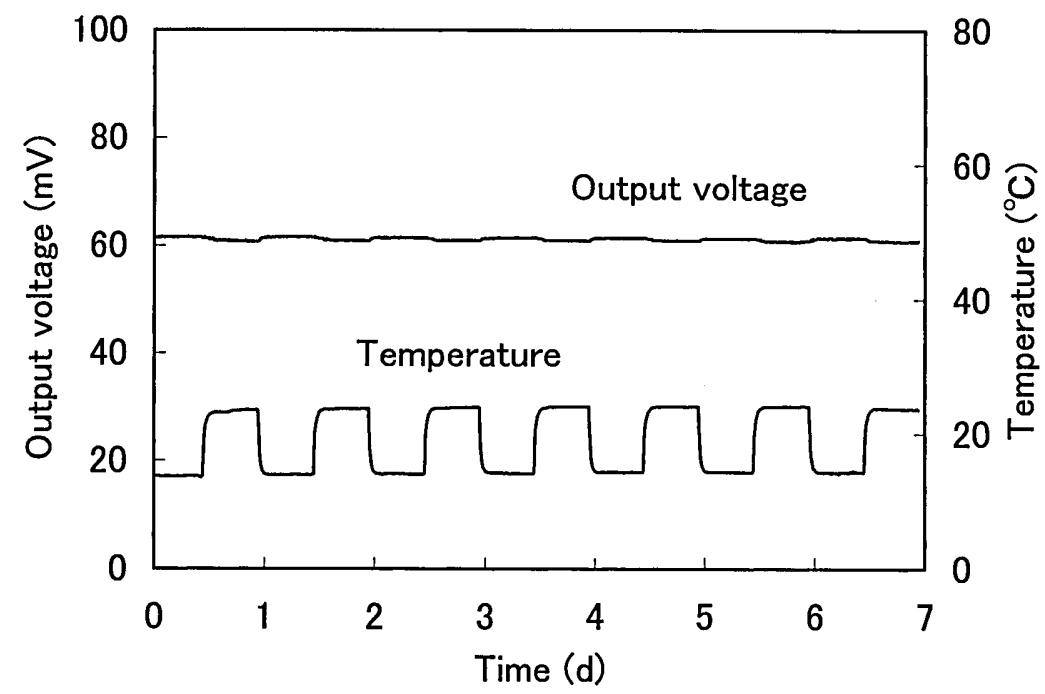

Fig. 4. Temperature and time stability of input circuit. Voltage of $61 \mathrm{mV}$ was continuously applied to the circuit for 7 days under the condition of temperature changing periodically. 


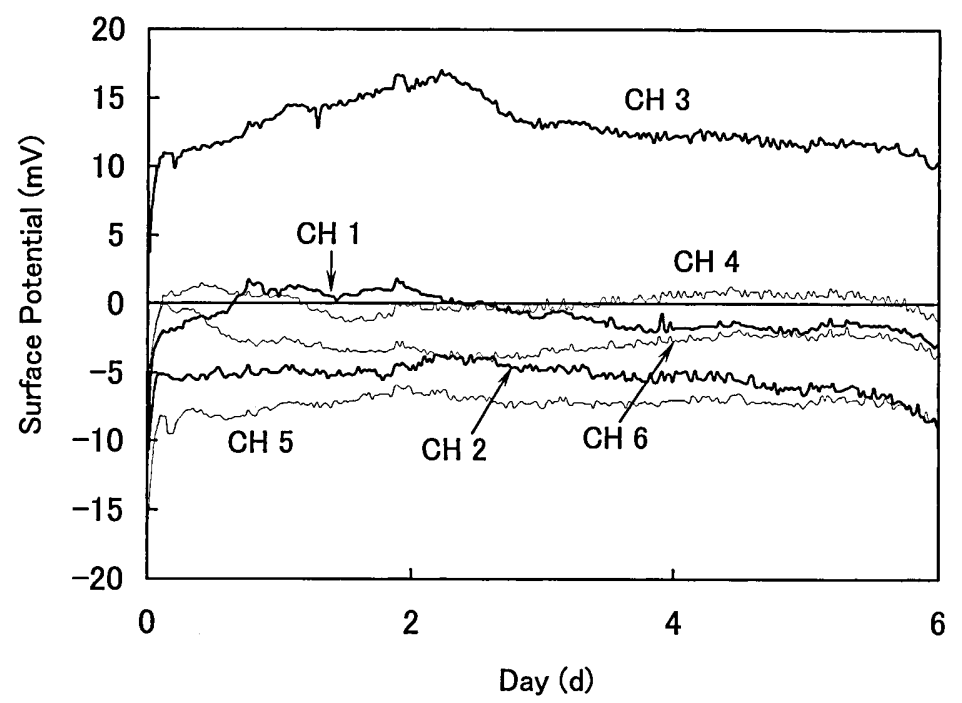

Fig. 5. Changes in surface potential of tomato fruit at 6 different positions on tomato surface.

has no considerable difference caused by the position on the equator. Moreover, another preliminary test indicated that there was no remarkable difference in the surface potential between on a loculus tissue and on a loculus tissue wall. Consequently, the surface potential less depended on the position of tomato surface. Accordingly one or two channels were used in the subsequent experiments.

\section{Change in surface potential with elapsed time (Exp. 1)}

Fig. 6 shows the changes in the surface potential and the respiration rate of tomato fruit at $13^{\circ} \mathrm{C}$. Surface potential A and B represent the potential at two different positions on the tomato surface. Both A and B slightly and irregularly changed with time, and their behaviors were almost same as shown in Fig. 4. The surface potential change observed is natural as Sekiyama and Hanyu (1985) also described. The slight and irregular change in the surface potential with time is hereinafter called "stray change". The respiration rate was fluctuated in the range from 5 to $18 \mathrm{CO}_{2} \mathrm{mg} \mathrm{kg}^{-1} \mathrm{~h}^{-1}$, and gradually decreased with time because of a developmental change.

\section{Effect of temperature on surface potential (Exp. 2)}

The surface potential of tomato fruit under the condition of temperature changing is shown in Fig. 7. Temperature of tomato fruit rose from 12.5 to $22.5^{\circ} \mathrm{C}$ at $1.2 \mathrm{~d}$ after beginning of experiment, simultaneously the surface potential started to change. This change was not considered as "stray change" due to rapid and large increase. As the input circuit was not affected by temperature (Fig. 4), the surface potential clearly depended on temperature. After $1.5 \mathrm{~d}$ when temperature was kept at $22.5^{\circ} \mathrm{C}$, the surface potential slightly decreased. The respiration rate of tomato fruit, in the same manner as the sur- 


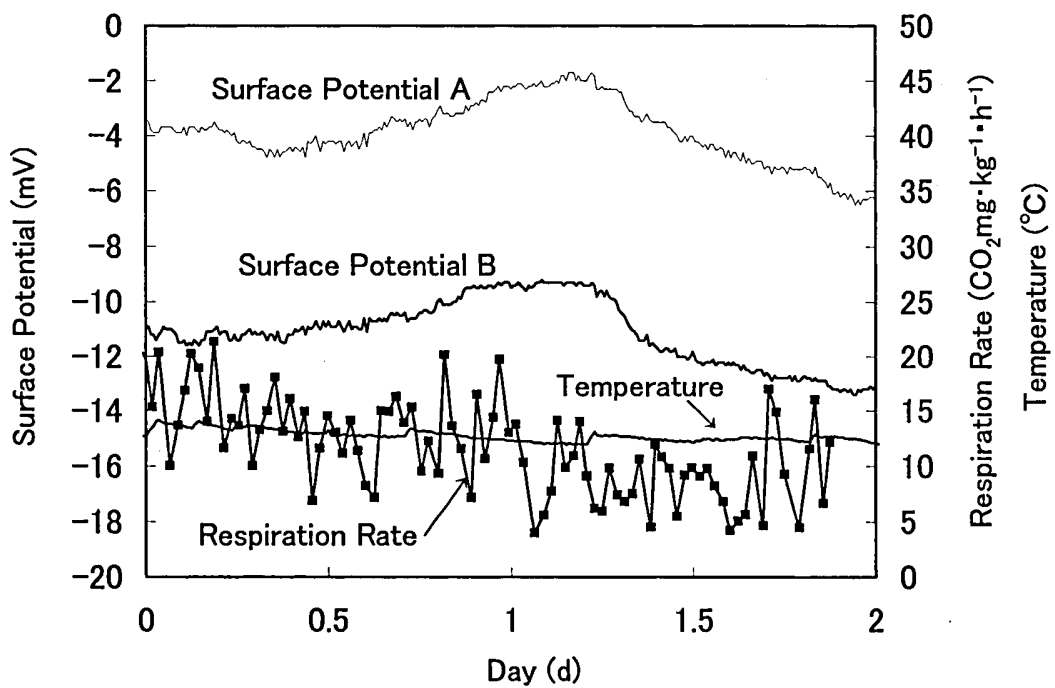

Fig. 6. Time course of surface potential and respiration rate of tomato fruit at $13^{\circ} \mathrm{C}$ (Exp. 1).

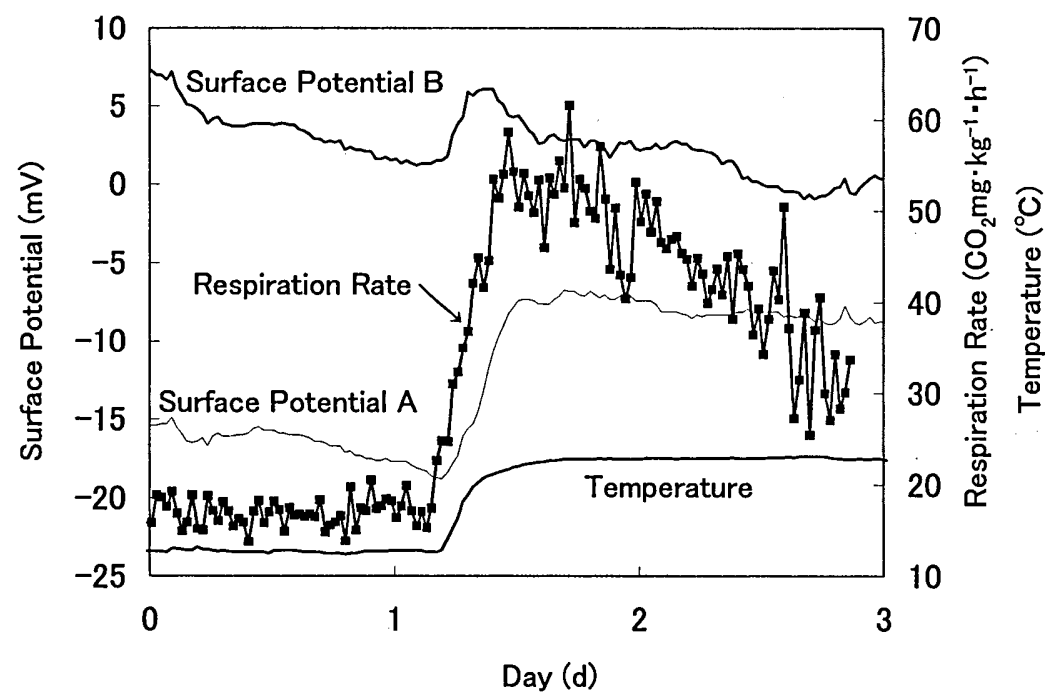

Fig. 7. Changes in surface potential and respiration rate of tomato fruit under the condition of temperature changing (Exp. 2). 
face potential, rapidly increased with rise in temperature, and then it turned to decrease after temperature became constant, nevertheless reduction rate of respiration rate was greater than that of surface potential.

Only from the result of Exp. 2, it was not clear to say which temperature or respiration rate affected the surface potential, so that the Exps. 3 and 4 were prepared to individually evaluate the effects of respiration and temperature.

\section{Change in surface potential under anoxia (Exp. 3)}

Fig. 8 shows the changes in the surface potential of tomato fruit under anoxia. Although temperature rose from 14 to $23^{\circ} \mathrm{C}$, the respiration rate did not change with temperature. The surface potential was almost constant despite of temperature change. Slight fluctuation of the surface potential could be considered as "stray change". The results of Exps. 2 and 3 demonstrated that the surface potential was changed with temperature, while it was strongly dependent on the respiration.

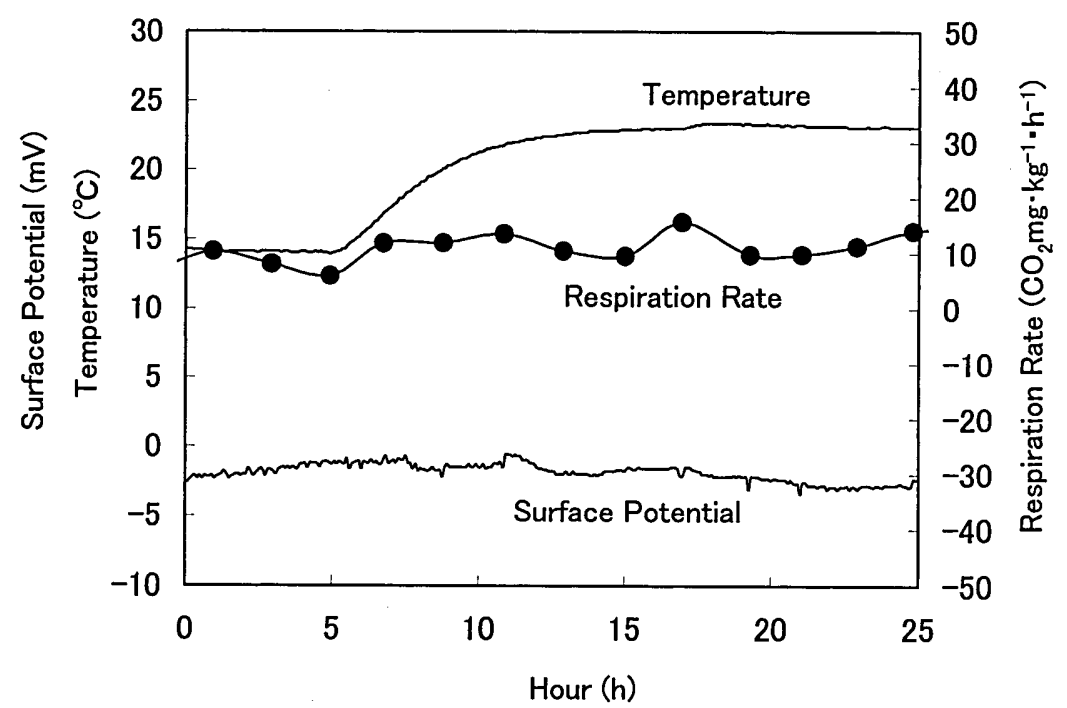

Fig. 8. Changes in surface potential and respiration rate of tomato fruit under anoxia (Exp. 3).

\section{Change in surface potential at climacteric stage (Exp. 4)}

Fig. 9 shows the changes in the surface potential and the respiration rate of tomato fruit under climacteric stage at a constant temperature of $24.5^{\circ} \mathrm{C}$. The respiration showed a typical climacteric rise. The respiration rate began to rise at $2.2 \mathrm{~d}$, and turned to decrease at $7.6 \mathrm{~d}$. On the other hand, surface potential began to rise at around $2 \mathrm{~d}$, and turned to drop at 4.5 or $5 \mathrm{~d}$. Finally it returned to the initial level at about $6.5 \mathrm{~d}$. The behavior of the surface potential at climacteric stage differed from that in Exp. 2. 


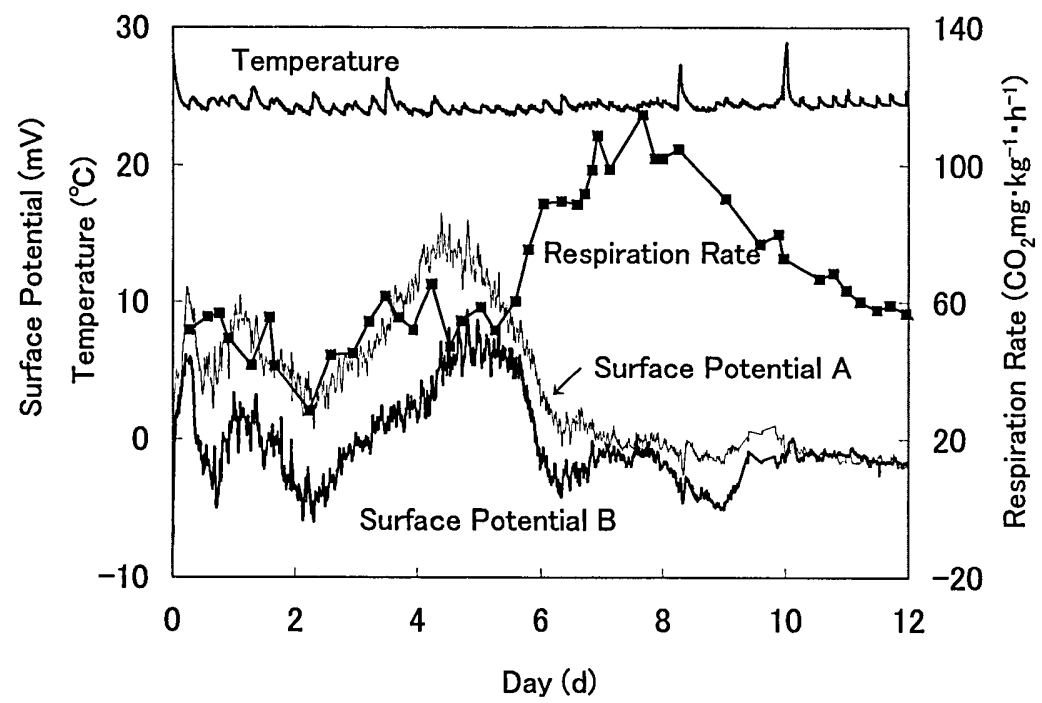

Fig. 9. Changes in surface potential and respiration rate of tomato fruit at climacteric stage (Exp. 4).

\section{DISCUSSION}

The slight and irregular change ("stray change") in surface potential shown in Figs. 2 and 3 was also described by Sekiyama and Hanyu (1985), it was naturally observed when a bioelectric potential was measured (for example, Tomiyama et al., 1983). The "stray change"s of different channels were similar each other, but the behaviors did not perfectly synchronize. In addition, a magnitude of potential on a position was different from that on others. However, no particular tendency due to the position was obtained, namely, the relative position of the measuring electrode to the referring electrode did not make a particular order of the potential. Kano and Yamaguchi (1996) measured the surface potential along the axis of cucumber fruit and described the potential was higher at apical part but lower at center of fruit. They sugested the difference in the potential among different positions on the surface of cucumber fruit was dependent on the difference in the metabolism concerning with fruit growth between stalk part and point part. While it was not appropriate to consider that the difference obtained in the present research was caused by the metabolism because there was no difference in growth among the positions on the equator and the tomato fruits used were at a red stage when growth of tomato fruit has already finished.

The bioelectric potential such as the surface potential is generated by the difference in ion level between the inside and outside of plasmalemma or tonoplast. It is known as the membrane potential. Since Higinbothan et al. (1970) strongly proposed that there are electrogenic ion pumps in higher plant cell. The membrane potential $E_{m}$ has been thought to consist of electrogenic potential $E_{p}$ and passive diffusion potential $E_{d}$, namely $E_{m}=E_{p}+E_{d}$ (Slayman et al., 1973; Shimmen and Tazawa, 1977; Tomiyama et al., 1983; Tomiyama et al., 1987). The surface potential measured in this study seems to result 
from $E_{m}$. The electrogenic potential depends on the metabolism such as respiration and photosynthesis (Higinbothan, 1973), so-called the metabolism dependent potential. That is to say, there are ion channels which generate $E_{d}$ and $\mathrm{H}^{+}$pump channels which generate $E_{p}$ by using energy of ATP. As the tomato fruits didn't photosynthesize in the situation of present research, the metabolism dependent potential was considered the respiration-dependent electrogenic potential.

The surface potential was apparently affected by temperature as shown in Exp. 2 . Respiration is a series of enzyme reaction so that respiration rate changes with temperature conforming to Arrhenius' equation. Moreover, oxidative phosphorylation in the respiratory chain depends on temperature. Therefore, it is considered that $E_{p}$ changes with temperature. However, it was not clear that the change in surface potential in Exp. 2 was caused by the change in $E_{p}$, because $E_{d}$ also increases on account of activation of ion diffusion by temperature rise as given by Goldman's equation as follows:

$$
E_{d}=-\frac{R T}{F} \ln \frac{\sum_{j} P_{j}^{+} C_{j}^{i}+\sum_{k} P_{k}^{-} C_{k}^{o}}{\sum_{j} P_{j}^{+} C_{j}^{o}+\sum_{k} P_{k}^{-} C_{k}^{i}}
$$

where $R$ is the gas constant; $T$ the absolute temperature; $F$ the Faraday constant; $P$ the permeability coefficient; $C$ the concentration; $i$ and $o$ represent in and out, respectively.

When respiration inhibitor such as cyanide is applied or a plant is exposed under anoxia, the electrogenic ion pump is inactivated and $E_{m}$ is depolarized (Higinbotham et al., 1970; Katou, 1978; Mimura et al., 1982). In Exp. 3 the tomato fruit was left in the condition of oxygen deficiency where electrogenic potential was considered to be zero, therefore only the dependence of diffusion potential $E_{d}$ on the surface potential was determined. The surface potential in the Exp. 3 was almost constant regardless of temperature. Considering the results of Exps. 2 and 3 at issue together, change in the surface potential in Exp. 2 obviously depended on the electrogenic potential $E_{p}$, Namely, the potential on tomato fruit surface depended not on temperature but on respiration.

In order to clarify the relation between surface potential and respiration, Exp. 4 was carried out using a tomato fruit at the climacteric stage when temperature was constant. The surface potential apparently changed with respiration rate at the onset of climacteric rise (at $2 \mathrm{~d}$ ), and began to decrease despite of respiration increasing at $5 \mathrm{~d}$. From the results of Exps. 2, 3 and 4, the surface potential obtained in this study was considered to depend on the respiration of tomato fruit.

\section{CONCLUSION}

The surface potentials on harvested tomato fruits were measured under various conditions. The effects of temperature and respiration rate of the fruits on the surface potential were investigated. The surface potential slightly and irregularly changed with elapsed time at a constant temperature but drastically changed with temperature rise except for under anoxia. Therefore the change in the surface potential with temperature depended only on respiration-dependent electrogenic potential. On the other hand, the surface potential initially increased with respiration rate at the climacteric stage, and turned to 
decrease before the respiration decreasing. From these results the surface potential obtained in this study was considered to depend on the respiration of tomato fruit.

The present results suggest that the respiration rate of the harvested fruits is possibly predicted by measuring the surface potential. If further data are obtained, the potential may be useful for monitoring storage condition and evaluating maturity of climacteric type fruit.

\section{ACKNOWLEDGEMENT}

This work was supported by a grant-in-aid for scientific research from the Ministry of Education, Science, Sports and Culture of Japan.

\section{REFERENCES}

Fromm, J. and T. Bauer 1994 Action potential in maize sieve tubes change phloem translocation. $J$. Exp. Bot., 45: 463-469

Fromm, J., M. Hajirezaei and I. Wilke 1995 The Biochemical Response of Electrical Signaling in the Reprouctive System of Hibiscus Plants. Plant Physiol., 109: 375-384

Fromm, J. and H. Fei 1998 Electrical Signaling and Gas Exchange in Maize Plants of Drying Soil. Plant Sci., 132: 203-213

Higinbothan, N., J. S. Graves and R. F. Davis 1970 Evidence for Electrogenic Ion Pump in Cells of Higher Plants. J. Memb. Biol., 3: 210-222

Higinbothan, N. 1973 Electropotentials of Plant Cells. Ann. rev. Plant Physiol., 24: 25-46

Intabon, K., T. Maekawa and K. Sato 1996 Studies on the Monitoring Techniques and application of bioelectric potentials in bioproduction. J. Soc. Agric. Struc. Japan, 27: 141-148

Kano, Y. and M. Yamaguchi 1996 Measurement of Electrical Potential of Plant Surface using MOSFET by Channel Chopping Method. Environ. Cont. Biol., 34: 209-214 (in Japanese with English abstract)

Katou, K. 1978 Distribution of electric potential and transport in the hypocotyl of Vigna sesquipedalis, V. Electrogenic activity of the parenchyma cells in hypocotyl segments. Plant Cell Physiol., 19: $523-535$

Mimura, T., T. Shimmen and M. Tazawa 1982 Respiration-dependent membrane hyperpolarization in tonoplast-free cells of Nitella axilliformis. Plant Cell Physiol., 23: 1419-1425

Miwa, Y., Y. Kushihashi and M. Sasagawa 1992 Behavior of bioelectric potential on the leaf surface under the sound stimulus. Environ. Cont. Biol., 30: 29-35 (in Japanese with English abstract)

Morimoto, T., J. De Baerdemaeker and Y. Hashimoto 1997 An intelligent approach for optimal control of fruit-storage process using neural networks and genetic algorithms. Computers and electronics in agriculture, 18: 205-224

Nakabayashi, K. and K. Matsumoto 1999 Diagnosis of Nutritional Disorders in Plants Based on the Bioelectric Potential on Leaf Surface of Tomato Plants. J. Soc. High Technol. Agric., 11: 189-200 (in Japanese with English abstract)

Nakabayashi, K., G. Tanaka and M. Kurita 2000 Nutrient Diagnosis of Tomato using the Spesific Frequency of Leaf Electric Potential. J. Soc. High Technol. Agric., 12: 112-116 (in Japanese with English abstract)

Sekiyama, T. and H. Hanyu 1985 Continuous measurement of electrical characteristics in plant (1). Technical report of Central Research Institute of Electric Power Industry, No. 484002: 1-19 (in Japanese with English abstract)

Shimmen, T. and M. Tazawa 1977 Control of Membrane Potential and Excitability of Chara Cells with ATP and $\mathrm{Mg}^{2+}$. J. Memb. Biol., 37: 167-192

Slayman, C. L., W. S. Long and C. Y. -H. Lu 1973 The Relationship between ATP and an Electrogenic Pump in the Plasma Membrane of Neurospora crassa. J. Memb. Biol., 14: 305-338

Tomiyama, K., H. Okamoto and K. Katou 1983 Effect of infection by Phitophthora infestans on the membrane potential of potato cell. Physiol. Plant Pathol., 22: 233-243 
Tomiyama, K., H. Okamoto and K. Katou 1987 Membrane potential change induced by infection by Phytophthora infestans of potato cells. Ann. Phytopath. Soc. Japan, 53: 310-322

Uchida, T., Y. Nakanishi and M. Urata 1990 Studies on Measurement of Bioelectric Potential of Intact Plant for Environmrntal Control (Part 1), Measurement of Bioelectric Potential on the Surface of Spinach lamina. Environ. Cont. Biol., 28: 113-118 (in Japanese with English abstract) 